\title{
Reduced serum brain-derived neurotrophic factor in patients with first onset vitiligo
}

\author{
This article was published in the following Dove Press journal: \\ Neuropsychiatric Disease and Treatment \\ 12 December 2014 \\ Number of times this article has been viewed
}

\section{Emin Yanik' \\ Gamze Erfan' \\ Yakup Albayrak ${ }^{2}$ \\ Murat Aydin ${ }^{3}$ \\ Mustafa Kulac' \\ Murat Kuloglu ${ }^{4}$}

'Department of Dermatology, Faculty of Medicine, Namık Kemal University, Tekirdag, Turkey; ${ }^{2}$ Department of Psychiatry, Faculty of Medicine, Namık Kemal University, Tekirdag, Turkey; ${ }^{3}$ Department of Biochemistry, Faculty of Medicine, Namık

Kemal University, Tekirdag, Turkey; ${ }^{4}$ Department of Psychiatry, Faculty of Medicine, Akdeniz University, Antalya, Turkey
Correspondence: Gamze Erfan Namık Kemal Universitesi Uygulama ve Arastırma Hastanesi Dermatoloji Poliklinigi Tunca Cad, 100 Yıl mah,

Tekirdag, Turkey

Tel +90282 2505179

$\mathrm{Fax}+902822509950$

Email gamzeerfan@gmail.com
Purpose: Vitiligo is an acquired pigmentary skin disease that can cause serious cosmetic problems. There have been numerous and well established studies that have demonstrated the comorbidity of various psychiatric disorders in patients with vitiligo. However, to our knowledge, there have been no studies investigating whether a psychiatric biomarker, such as brain-derived neurotrophic factor (BDNF), is associated with vitiligo.

Patients and methods: This study was conducted in Nam1k Kemal University Medical Faculty, Departments of Dermatology and Psychiatry between January 2013 and September 2014. After meeting inclusion and exclusion criteria, serum BDNF levels were assayed in 57 patients with first onset vitiligo and no known current or past psychiatric disorder and compared with BDNF levels in 58 age and sex matched healthy subjects.

Results: The age and female/male ratios were similar between groups. The mean values of serum BDNF were $1.57 \pm 0.97 \mathrm{ng} / \mathrm{dL}$ and $2.37 \pm 1.73 \mathrm{ng} / \mathrm{dL}$ in the vitiligo group and in the healthy control group, respectively. The mean BDNF level was significantly higher in the healthy control group compared with the vitiligo group $(t=2.76, P=0.007)$.

Conclusion: This is the first study to compare serum BDNF levels between patients with vitiligo and healthy subjects. The reduced level of serum BDNF in patients with vitiligo may be directly related to the etiology of vitiligo or associated with the high percentage of psychiatric disorders in that patient population. Further studies are needed to support our preliminary results.

Keywords: neurotrophin, psychosomatic, skin, disease

\section{Introduction}

Vitiligo is an acquired pigmentary skin disease that is characterized by the development of white macules resulting from the loss of pigment producing cells. ${ }^{1}$ The disorder can develop at any age and has a prevalence of approximately $1 \%{ }^{2}$ The etiology of vitiligo is unclear though factors such as autoimmunity, oxidative imbalance, and sympathetic neurogenic disturbance are thought to contribute to the pathophysiology of this skin disorder. ${ }^{3}$ Vitiligo is commonly asymptomatic. However, patients with vitiligo can experience a high degree of social functional impairment. ${ }^{4}$ There have been numerous studies exploring the relationship between psychiatric disorders or symptoms and vitiligo. Vitiligo patients are reported to have high scores of anxiety, depressive disorder, generalized anxiety disorder, social phobia, obsessive symptoms and hypochondria, high rates of alexithymia and avoidance behavior, and high rates of sleep disturbances. ${ }^{5-8}$ Stigmatization can be strongly associated with the negative psychosocial impact in patients who suffer from vitiligo. ${ }^{9}$ Furthermore, we have previously reported that patients with vitiligo have a distinct temperament and character profile compared with healthy controls and patients with alopecia areata. ${ }^{10}$ Vitiligo is of great interest in the field of psychosomatic disorders because of the associated psychiatric comorbidities. 
Brain-derived neurotrophic factor (BDNF) is one of the most important and most researched neurotrophins that regulates synaptic plasticity. BDNF is also crucial for learning and memory processes. ${ }^{11}$ It has been established that BDNF signaling in the mature human brain modulates behavior. Furthermore, in addition to its important role in learning and memory, BDNF has been associated with mood related behaviors as well as cognition. Thus, BDNF is widely studied in neuropsychiatric disorders such as schizophrenia, major depressive disorder, bipolar disorder, addiction, and eating disorders. $^{12}$

Previous data investigating the association between vitiligo and psychiatric disorders commonly noted that the latter emerged as a consequence of vitiligo. To our knowledge, no study has investigated serum BDNF levels in vitiligo patients without evidence of psychiatric comorbidities. Thus, we aimed to investigate whether patients with vitiligo have a biological predisposition to developing psychiatric disorders by assessing serum BDNF levels.

\section{Material and methods}

The present study was conducted in Namık Kemal University Medical Faculty, Departments of Dermatology and Psychiatry between January 2013 and September 2014. We enrolled consecutive patients admitted to the dermatology outpatient service with a diagnosis of first onset vitiligo. The definition of first onset vitiligo was clinically determined and included patients who were admitted to the dermatology outpatient service with a first time diagnosis of vitiligo and who had no previous diagnosis of any skin disease before admission to the service. All patients were referred to a senior psychiatrist for psychiatric assessment. Exclusion criteria included: subjects who were younger than 18 years old and older than 60 years old, who had a history of any psychiatric disorder or were diagnosed with a psychiatric disorder after the psychiatric examination, who had another dermatologic disease, who were following a food restriction diet for medical reasons or who were voluntarily dieting, and who did not want to participate in the study. After exclusions, 57 patients with first onset vitiligo were included in the present study. Fifty-eight age and sex matched healthy subjects consisting of hospital staff were recruited as controls. The severity of vitiligo was assessed using the "rule of nine". The severity of anxiety and depression was assessed by the Beck Depression Inventory (BDI) and Beck Anxiety Inventory (BAI) in both the vitiligo and healthy control groups. The patients with vitiligo were also evaluated using the dermatology life quality index (DLQI).
Both patients and healthy subjects were given informed consent forms and agreed to participate in the study. The study protocol was approved by the institutional ethical committee.

\section{Biochemical procedure}

Blood samples were collected between 8 am and 10 am, after an overnight fast of at least 12 hours. The serum was extracted from the whole blood sample by centrifugation at 2,000 rpm for 15 minutes and frozen immediately. All serum samples were preserved at $-80^{\circ} \mathrm{C}$ until analysis. Using a double-antibody sandwich enzyme-linked immunosorbent assay (ELISA) technique, BDNF serum levels were determined using a commercial kit (Sunred Biological Technology, Shanghai, People's Republic of China). The samples were processed according to the manufacturer's instructions. The standard curve ranged from $0.1 \mathrm{ng} / \mathrm{mL}$ to $10 \mathrm{ng} / \mathrm{mL}$ of BDNF and showed a direct relationship between the optical density and the concentration of BDNF. Two determinations of BDNF levels were made for each sample, and the result was taken as the mean of both determinations. Analytic sensitivity of BDNF ELISA is $0.05 \mathrm{ng} / \mathrm{mL}$.

\section{Rule of nine}

The "rule of nine" assessment involves the evaluation of the head and neck, each arm, leg, and the four trunk quadrants for vitiligo patches, each comprising $9 \%$ of the total body surface area with the genitalia comprising $1 \%$. Using the Wood's lamp examination of depigmentation of vitiligo patients, the severity of disease is assessed with the rule of nine, which has been described as subjective and based on visual assessments. ${ }^{13}$

\section{BAI}

The BAI is a self-report scale designed to evaluate the severity of physical symptoms of anxiety. Participants rate the 21 items on a 4-point Likert type severity scale from $0=$ "not at all" to 3= "severely, I could barely stand it". Total response scores range from 0 to 63 , with higher scores indicating more severe anxiety. ${ }^{14}$

\section{BDI}

The BDI is a self-report scale designed to evaluate the severity of depressive symptoms as well as the tendency toward depression in patients. Participants rate 21 items on a 4-point Likert type severity scale from $0=$ "not at all" to 3 . Total response scores range from 0 to 63 , with higher scores indicating more severe depression. ${ }^{15}$ 


\section{DLQI}

DLQI is an easy, self-administered survey that is the most commonly used 10-item questionnaire. It consists of questions that evaluate patients' perceptions of the impact of the skin disease on such parameters as feelings, daily activities, leisure, work and school, personal relationships, and side effects of the treatment over the last week. The total score is 30 and higher scores define greater impairment of quality of life..$^{16,17}$

\section{Statistical methods}

Data were analyzed using the Statistical Package for the Social Sciences-PC version 18.0 (SPSS Inc., Chicago, IL, USA). A confidence interval of $95 \%$ and a two tailed $P$-value less than 0.05 were considered statistically significant for all analyses. All numerical variables were tested by the KolmogorovSmirnov test for normality of distribution. Differences between groups in terms of age, level of serum BDNF, scores of BAI, and BDI were tested with independent sample $t$-tests. Differences between sexes were compared with $\chi^{2}$ test. Pearson's correlation test was performed for analyzing the correlation coefficients between BDNF levels, age, scores of BAI, BDI and DLQI, and "rule of nine" in both groups separately.

\section{Results}

The mean ages were $43.63 \pm 13.48$ years and $40.45 \pm 13.23$ years in the vitiligo and healthy control group, respectively. The mean age was found to be similar between groups ( $t=0.91, P=0.61$ ). The male/female ratio was found to be similar between groups $\left(\chi^{2}=0.87, P=0.85\right)$. The mean values of serum BDNF were $1.57 \pm 0.97 \mathrm{ng} / \mathrm{dL}$ and $2.37 \pm 1.73 \mathrm{ng} / \mathrm{dL}$ in the vitiligo and healthy control group, respectively. The mean BDNF level was significantly higher in the healthy control group compared with the vitiligo group $(t=2.76$,

Table I Comparison of age, sex, BAI, BDI, and serum BDNF level in subjects with vitiligo and healthy control groups

\begin{tabular}{|c|c|c|c|}
\hline & Vitiligo $(\mathrm{N}=57)$ & $\begin{array}{l}\text { Healthy controls } \\
(\mathrm{N}=58)\end{array}$ & Statistic \\
\hline Age (years) & $43.63 \pm 13.48$ & $40.45 \pm 13.23$ & $t=0.91, P=0.6 \mathrm{I}$ \\
\hline \multicolumn{4}{|l|}{ Sex, n (\%) } \\
\hline Female & 32 (55.2\%) & 33 (57.9\%) & \multirow[t]{2}{*}{$\chi^{2}=0.87, P=0.85$} \\
\hline Male & 26 (44.8\%) & 24 (42.1\%) & \\
\hline BAI & $10.24 \pm 9.04$ & $10.17 \pm 7.87$ & $t=-0.46, P=0.94$ \\
\hline BDI & $11.21 \pm 7.32$ & $10.62 \pm 7.47$ & $t=-0.38, P=0.71$ \\
\hline $\begin{array}{l}\text { BDNF level } \\
\text { (ng/dL) }\end{array}$ & $1.57 \pm 0.97$ & $2.37 \pm 1.73$ & $t=2.76, P=0.007$ \\
\hline
\end{tabular}

Note: Data in the Vitiligo and Healthy control columns are shown as mean \pm standard deviation unless otherwise stated.

Abbreviations: BDNF, brain-derived neurotrophic factor; BAI, Beck Anxiety Inventory; BDI, Beck Depression Inventory.
$P=0.007$ ) (Table 1, Figure 1). The mean scores of BAI were $10.24 \pm 9.04$ and $10.17 \pm 7.87$ in the vitiligo and healthy control group, respectively. The mean scores of BDI were 11.21 \pm 7.32 and $10.62 \pm 7.47$ in the vitiligo and healthy control group, respectively. The mean scores of BAI and BDI were similar between groups $(P>0.05)$ (Table 1). The mean value of DLQI was $7.57 \pm 4.451$ in the vitiligo group. The mean value of "rule of nine" was $5.13 \% \pm 3.42 \%$ in the vitiligo patients.

There was no significant correlation between mean serum BDNF level, mean age, mean scores of BAI, BDI, DLQI, and mean value of "rule of nine" in the vitiligo group. There was also no significant correlation between mean serum BDNF levels and the mean age, mean scores of BAI and BDI in the healthy control group (Table 2).

\section{Discussion}

Psychiatric morbidity in vitiligo patients has been broadly studied. Porter et al reported a high rate of depression and low self-esteem in patients with vitiligo. ${ }^{18}$ In another study, the prevalence of psychiatric disorders was approximately $35 \%{ }^{19}$ The Indian studies reported a high percentage of adjustment disorders $(56 \%-75 \%)$, depression (10\%), dysthymia (7\%-9\%), sleep disturbance (20\%), suicidal ideation $(10 \%)$, and anxiety (3\%). ${ }^{8,20,21}$ A study comparing patients with vitiligo and chronic urticaria with respect to the presence of psychiatric comorbidities, revealed that patients with vitiligo had a higher rate of social phobia, dysthymia, obsessive compulsive disorder, and specific phobias. ${ }^{22}$ Recently, Noh et al evaluated the degree of psychological stress and impairment of quality of life in a total of 60 patients from each group with vitiligo, atopic dermatitis patients, and healthy controls. They showed that vitiligo involves less psychological impact than atopic dermatitis..$^{23}$ In a recent study, Krüger and Schallreuter compared stigmatization, avoidance behavior, and difficulties in coping in 96 patients with vitiligo and 23 control subjects. They reported that stigmatization was common in $90 \%$ of patients with vitiligo.$^{24}$ In line with our findings, the two studies previously mentioned, found that the depression scale was similar for both patients with vitiligo and healthy controls. Though vitiligo is known to be a more emotionally disabling disease, there are frequent reports of low DLQI scores in these patients. This finding is thought to be due to the low incidence of depression. ${ }^{25,26}$ These previous findings suggest that there has not been any established consensus about the presence of psychiatric comorbidities in patients with vitiligo.

Neurotrophins are one of the most important signaling factors that play a leading role in axon targeting, neuronal 
Table 2 Correlation coefficients BDNF, age, BAI, BDI, DLQI, and the value of "rule of nine" in vitiligo and healthy control groups

\begin{tabular}{lllllll}
\hline & & Age & Rule of nine & BAl & BDI & DLQI \\
\hline Vitiligo & BDNF & $r=-0.027$ & $r=0.067$ & $r=0.005$ & $r=0.04$ & $r=0.092$ \\
& & $P=0.90$ & $P=0.86$ & $P=0.97$ & $P=0.77$ & $P=0.49$ \\
Healthy control & BDNF & $r=-0.205$ & - & $r=-0.07$ I & $r=0.122$ & - \\
& & $P=0.122$ & & $P=0.59$ & $P=0.36$ \\
\hline
\end{tabular}

Abbreviations: BDNF, brain-derived neurotrophic factor; BAI, Beck Anxiety Inventory; BDI, Beck Depression Inventory; DLQI, dermatology life quality index.

growth, and synaptic plasticity. Of these neurotrophins, BDNF, is the best known. BDNF's role in synaptic plasticity has been well established. It is also thought to have a number of potential roles in both the etiology and treatment of many psychiatric disorders. ${ }^{27,28}$ During development, $\mathrm{BDNF}$ is important for proper axonal growth. ${ }^{29} \mathrm{BDNF}$ is also considered to be essential for the development and survival of dopaminergic, serotonergic, GABAergic, and cholinergic neurons. ${ }^{30}$ The cellular reactions following BDNF signaling develop within seconds and can support long-term potentiation that enhances synaptic strengths between neurons. ${ }^{31}$

BDNF is one of the most well studied and established neurotrophins in the field of neuropsychiatry. There have been numerous preclinical and clinical studies that have investigated the association between BDNF levels and major depressive disorders, anxiety related disorders, response to stressful events, schizophrenia, bipolar disorders, eating disorders, addiction disorders, and neurodevelopmental disorders. Most of them found that decreased BDNF levels were potentially associated with the development of the aforementioned psychiatric disorders. Furthermore, numerous studies have reported improvement in BDNF levels after appropriate treatment. ${ }^{12}$ While many studies have investigated psychiatric comorbidities in patients with vitiligo, there have been more reports about depressive disorders, anxiety disorders, and increased stress in these patients than psychotic disorders such as schizophrenia, bipolar disorder, etc. In particular, several studies have reported decreased serum BDNF levels in patients with depressive disorders. Further, serum BDNF was considered to be a good candidate biomarker for major depressive disorders. ${ }^{32-37}$ In a systematic review and meta-regression analysis, BDNF levels were found to vary in individuals with and without anxiety disorders, though levels were lower in those with an anxiety disorder. ${ }^{38}$ BDNF levels are also reduced during stressful events in both animal and human studies. ${ }^{39-43}$

The role of neurotrophins and their receptors has been recently defined in the control of skin hemostasis and hairgrowth. ${ }^{44-48}$ Botchkarev et al reviewed the molecular mechanisms of normal skin and stress induced hair loss,

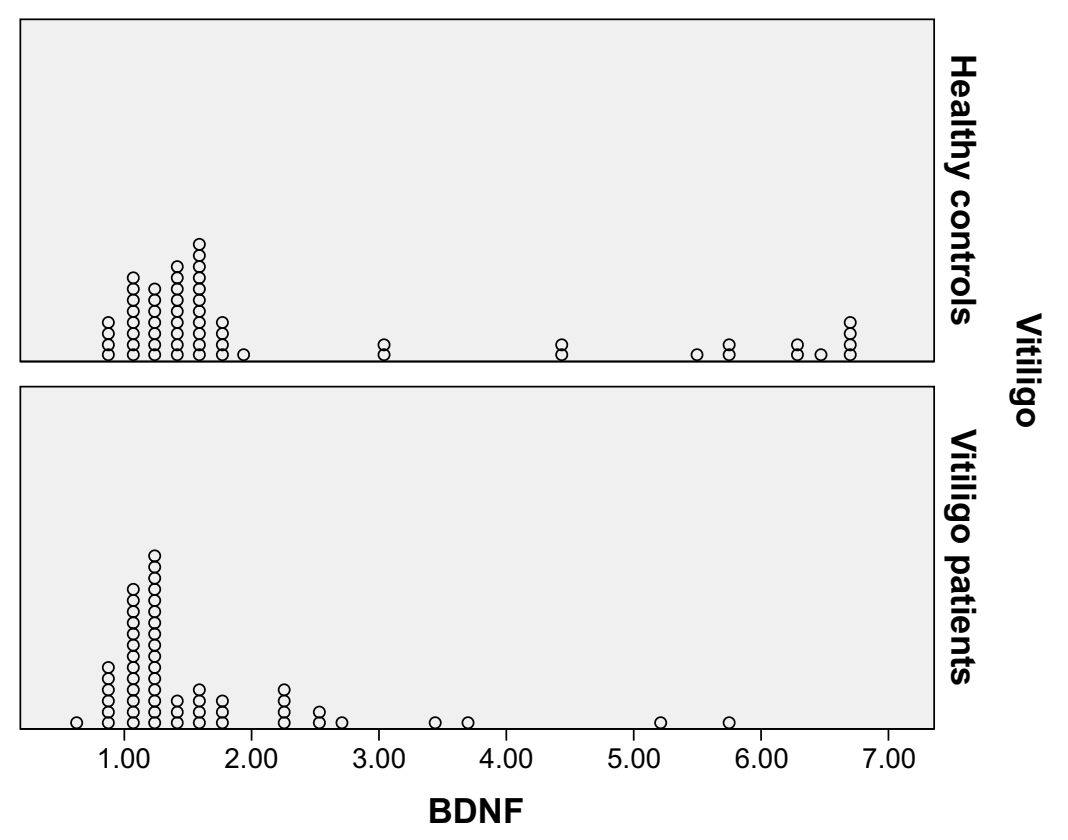

Figure I The dot plot figure of BDNF in patients with vitiligo and healthy controls. Abbreviation: BDNF, brain-derived neurotrophic factor. 
psoriasis, and atopic dermatitis. ${ }^{49} \mathrm{BDNF}$ is a member of a family of neurotrophins. In skin, BDNF is produced by fibroblasts in vivo, while it is expressed in cutaneous nerve fibers and myocytes of arrector pili and panniculus carnosus muscles in situ. ${ }^{48}$ Neurotrophins mediate proliferative and survival signals in epidermal keratinocytes ${ }^{46,48,50}$ and, similarly, influence the proliferation and survival of melanocytes. ${ }^{51,52}$ From an immunological perspective, T-lymphocytes are known to produce neurotrophins in the skin, but the sub-populations of T-lymphocytes in normal and diseased skin are not clear. ${ }^{53}$ In several skin diseases that are characterized by cell loss, hyper-proliferation, inflammation or autoimmune responses, there is increasing evidence that neurotrophins are involved in these pathogenic pathways. In acute psycho-emotional stress, it is known that nerve growth factor (NGF) is released into the bloodstream. ${ }^{54}$ NGF triggers the release of neuropeptides from sensory nerve fibers in skin $^{55,56}$ and can directly stimulate the release of proinflammatory cytokines. ${ }^{57,58}$ There has been some suggestion that NGF influences T-cell activation in psoriasis, but direct evidence is lacking. Neurotrophins can also influence numerous cellular functions in the skin with unknown cycles. ${ }^{59}$

Compared to skin diseases, only a limited number of studies have investigated the role of serum BDNF in the etiology of various neuropsychiatric disorders. ${ }^{60}$ Most research has focused on BDNF levels and $B D N F$ gene polymorphism in atopic dermatitis and most report increased BDNF levels in patients with atopic dermatitis. ${ }^{61,62}$ Because of the protective effects of neurotrophins, specifically BDNF, on immunoglobulin E, increased serum BDNF is considered to be a potential etiologic factor in atopic dermatitis in an indirect manner. A German study that investigated the variation of $B D N F$ and $N G F$ genes in the German population found no significant association between atopic dermatitis and gene variations. ${ }^{63}$ Increased serum BDNF levels have also been found to be associated with negative control signaling in androgenic alopecia. ${ }^{64}$

The etiology of vitiligo is still unclear. However, suspected etiological factors include genetic, autoimmune, humoral immunity, cellular immunity, neurohumoral theory, auto-cytotoxic hypothesis, the biochemical theory of vitiligo, oxidative stress hypothesis, melanocytorrhagy hypothesis, and decreased melanocyte survival hypothesis. ${ }^{2,65-72}$ Among these factors, the neurohumoral theory may pertain to our study. In this theory, dysregulation of the nervous system, either at a local or systemic level, may damage melanocytes in vitiligo. In support of this, both melanocytes and nerves arise from neural crest cells. Furthermore, some vitiligo is segmental, follows the distribution of nerves, and shows alterations during perspiration and changes in nerve structure.${ }^{67}$ Considering the regulatory role of BDNF within the nervous system, decreased serum BDNF in patients with vitiligo in our study may provide evidence to support the neurohumoral theory of vitiligo. As previously discussed, a high percentage of various psychiatric disorders exists in patients with vitiligo, which have often been explained as resulting from the cosmetic consequences of vitiligo. However, our preliminary results indicate that patients with vitiligo with no comorbid psychiatric disorder have decreased serum BDNF levels compared to age and sex matched healthy subjects. Thus, we propose that patients with vitiligo may have a predisposition to developing various psychiatric disorders compared with healthy subjects. Our study results suggest that a biomarker for psychosomatic disease may be present in patients with vitiligo, which may be significant in the field of psychosomatic disorders.

Our study has some limitations. BDNF is first produced as a precursor that is known as proBDNF. Although ELISA kits can measure BDNF, they are unable to distinguish between proBDNF and mature BDNF. ${ }^{73,74}$ Further studies that can measure both BDNF and proBDNF will be of great interest. Chronic diseases such as psychiatric disorders and skin diseases can impact the inflammatory process and alter the blood level of cytokines. ${ }^{75} \mathrm{We}$ did not measure serum interleukin (IL)2, IL6, and interferon- $\gamma$. However, future studies investigating these parameters would be of great interest.

\section{Conclusion}

To our knowledge, no study has investigated serum BDNF levels in patients with vitiligo. We suggest that our preliminary data seem to demonstrate a significant association between decreased serum BDNF levels and vitiligo. Our results suggest that reduced serum BDNF levels may be an etiologic factor in the development of vitiligo and may also be an indicator of future psychiatric comorbidity in patients with vitiligo. Further studies are needed to investigate BDNF and proBDNF in both serum and skin cells.

\section{Disclosure}

The authors report no conflicts of interest in this work.

\section{References}

1. Njoo MD, Westerhof W. Vitiligo pathogenesis and treatment. Am J Clin Dermatol. 2001;2(3):167-181.

2. Alikhan A, Felsten LM, Daly M, Petronic-Rosic V. Vitiligo: a comprehensive overview Part I. Introduction, epidemiology, quality of life, diagnosis, differential diagnosis, associations, histopathology, etiology, and work-up. J Am Acad Dermatol. 2011;65(3):473-491.

3. Taieb A, Picardo M. Clinical practice: Vitiligo. N Engl J Med. 2009; 360(2):160-169. 
4. Silvan M. The psychological aspects of vitiligo. Cutis. 2004;73(3): $163-167$.

5. Gieler U, Brosig B, Schneider U. Vitiligo-coping behavior. Dermatol Psychosom. 2000;1:6-10.

6. Mechri A, Amri M, Douarika AA. [Psychiatric morbidity and quality of life in vitiligo: a case controlled study]. Tunis Med. 2006;84:632-635. French.

7. Picardi A, Pasquini P, Cattaruzza MS. Stressful life events, social support, attachment security and alexithymia in vitiligo. A case-control study. Psychother Psychosom. 2003;72(3):150-158.

8. Sharma N, Koranne RV, Singh RK. Psychiatric morbidity in psoriasis and vitiligo: a comparative study. J Dermatol. 2001;28(8):419-423.

9. Ongenae K, Dierckxsens L, Brochez L. Quality of life and stigmatization profile in a cohort of vitiligo patients and effect of the use of camouflage. Dermatology. 2005;210(4):279-285.

10. Erfan G, Albayrak Y, Yanik ME, et al. Distinct temperament and character profiles in first onset vitiligo but not in alopecia areata. J Dermatol. 2014; 41(8):709-715.

11. Lu Y, Christian K, Lu B. BDNF: a key regulator for protein synthesis dependent LTP and long-term memory? Neurobiol Learn Mem. 2008;89(3):312-323.

12. Autry AE, Monteggia LM. Brain-derived neurotrophic factor and neuropsychiatric disorders. Pharmacol Rev. 2012;64(2):238-258.

13. Alghamdi KM, Kumar A, Taieb A, Ezzedine K. Assessment methods for the evaluation of vitiligo. J Eur Acad Dermatol Venereol. 2012; 26(12):1463-1471.

14. Beck AT, Epstein N, Brown G, Steer RA. An inventory for measuring clinical anxiety: Psychometric properties. J Consult Clin Psychol. 1988; 56(6):893-897.

15. Beck AT, Ward CH, Mendelson M, Mock J, Erbaugh J. An inventory for measuring depression. Arch Gen Psychiatry. 1961;4:561-571.

16. Finlay AY, Khan GK. Dermatology life quality index (DLQI) - a simple practical measure for routine clinical use. Clin and Exp Dermatol. 1994;19(3):210-216.

17. Ozturkcan S, Ermertcan AT, Eser E, Sahin MT. Cross validation of the Turkish version of dermatology life quality index. Int J Dermatol. 2006;45(11):1300-1307.

18. Porter J, Beuf AH, Nordlund JJ, Lerner AB. Psychological reaction to chronic skin disorders: a study of patients with vitiligo. Gen Hosp Psychiatry. 1979;1(1):73-77.

19. Kent G, Al'Abadie M. Psychologic effects of vitiligo: a critical incident analysis. J Am Acad Dermatol. 1996;35(6):895-898.

20. Parsad D, Dogra S, Kanwar AJ. Quality of life in patients with vitiligo. Health Qual Life Outcomes. 2003;1:58.

21. Mattoo SK, Handa S, Kaur I, Gupta N, Malhotra R. Psychiatric morbidity in vitiligo: prevalence and correlates in India. J Eur Acad Dermatol Venereol. 2002;16(6):573-578.

22. Sukan M, Maner F. Vitiligo ve kronik ürtiker hastalarında psikiyatrik eş tan [The psychiatric diagnosis of vitiligo and chronic urticaria]. Anadolu Psikiyatri Dergisi. 2007;8:30-36. Turkish.

23. Noh S, Kim M, Park CO, Hann SK, Oh SH. Comparison of the psychological impacts of asymptomatic and symptomatic cutaneous diseases: vitiligo and atopic dermatitis. Ann Dermatol. 2013;25(4):454-461.

24. Krüger C, Schallreuter KU. Stigmatisation, avoidance behavior and difficulties in coping are common among adult patients with vitiligo. Acta Derm Venereol. Epub 2014 Oct 1.

25. Kent G, al-Abadie M. Factors affecting responses on Dermatology Life Quality Index items among vitiligo sufferers. Clin Exp Dermatol. 1996; 21(5):330-333.

26. Basra MK, Fenech R, Gatt RM, Salek MS, Finlay AY. The Dermatology Life Quality Index 1994-2007: a comprehensive review of validation data and clinical results. Br J Dermatol. 2008;159(5):997-1035.

27. Lohof AM, Ip NY, Poo MM. Potentiation of developing neuromuscular synapses by the neurotrophins NT-3 and BDNF. Nature. 1993; 363(6427):350-353.

28. Kossel AH, Cambridge SB, Wagner U, Bonhoeffer T. A caged Ab reveals an immediate/instructive effect of BDNF during hippocampal synaptic potentiation. Proc Natl Acad Sci U S A. 2001;98(25):14702-14707.
29. Yoshii A, Constantine-Paton M. Postsynaptic BDNF-TrkB signaling in synapse maturation, plasticity, and disease. Dev Neurobiol. 2010;70(5): 304-322.

30. Pillai A. Brain-derived neurotropic factor/TrkB signaling in the pathogenesis and novel pharmacotherapy of schizophrenia. Neurosignals. 2008;16(2-3):183-193.

31. Nagappan G, Lu B. Activity-dependent modulation of the BDNF receptor TrkB: mechanisms and implications. Trends Neurosci. 2005;28(9): 464-471.

32. Shimizu E, Hashimoto K, Okamura N, et al. Alterations of serum levels of brain-derived neurotrophic factor (BDNF) in depressed patients without or with antidepressants. Biol Psychiatry. 2003;54(1):70-75.

33. Sen S, Duman R, Sanacora G. Serum brain-derived neurotrophic factor, depression, and antidepressant medications: meta-analyses and implications. Biol Psychiatry. 2008;64(6):527-532.

34. Brunoni AR, Lopes M, Fregni F. A systematic review and meta-analysis of clinical studies on major depression and BDNF levels: Implications for the role of neuroplasticity in depression. Int J Neuropsychopharmacol. 2008;11(8):1169-1180.

35. Bocchio-Chiavetto L, Bagnardi V, Zanardini R, et al. Serum and plasma BDNF levels in major depression: a replication study and meta-analyses. World J Biol Psychiatry. 2010;11(6):763-773.

36. Molendijk ML, Bus BA, Spinhoven P, et al. Serum levels of brain-derived neurotrophic factor in major depressive disorder: state-trait issues, clinical features and pharmacological treatment. Mol Psychiatry. 2011; 16(11):1088-1095.

37. Hashimoto K. Brain-derived neurotrophic factor as a biomarker for mood disorders: a historical overview and future directions. Psychiatry Clin Neurosci. 2010;64(4):341-357.

38. Suliman S, Hemmings SM, Seedat S. Brain-Derived Neurotrophic Factor (BDNF) protein levels in anxiety disorders: systematic review and meta-regression analysis. Front Integr Neurosci. 2013; 29(7):55.

39. Duman RS, Monteggia LM. A neurotrophic model for stress-related mood disorders. Biol Psychiatry. 2006;59(12):1116-1127.

40. Nibuya M, Takahashi M, Russell DS, Duman RS. Repeated stress increases catalytic TrkBmRNA in rat hippocampus. Neurosci Lett. 1999;267(2):81-84

41. Roceri M, Cirulli F, Pessina C, Peretto P, Racagni G, Riva MA. Postnatal repeated maternal deprivation produce sage-dependent changes of brain-derived neurotrophic factor expression in selected rat brain regions. Biol Psychiatry. 2004;55(7):708-714.

42. Kauer-Sant'Anna M, Tramontina J, Andreazza AC, et al. Traumatic life events in bipolar disorder: impact on BDNF levels and psychopathology. Bipolar Disord. 2007;9 Suppl 1:128-135.

43. Grassi-Oliveira R, Stein LM, Lopes RP, Teixeira AL, Bauer ME. Low plasma brain derived neurotrophic factor and childhood physical neglect are associated with verbal memory impairment in major depression a preliminary report. Biol Psychiatry. 2008;64(4):281-285.

44. Paus R, Peters EMJ, Eichmuller S, Botchkarev VA. Neural mechanisms of hair growth control. J Investig Dermatol Symp Proc. 1997;2(1): 61-68.

45. Pincelli C, Yaar M. Nerve growth factor: its significance in cutaneous biology. J Investig Dermatol Symp Proc. 1997;2(1):31-36.

46. Yaar M. Neurotrophins in skin. In: Sieber-Blum M, editor. Neurotrophins and the neural crest. London: CRC Press; 1999:117-140.

47. Bonini S, Rasi G, Bracci-Laudiero ML, Procoli A, Aloe L. Nerve growth factor: neurotrophin or cytokine? Int Arch Allergy Immunol. 2003; 131(2):80-84.

48. Botchkarev VA, Botchkareva NV, Peters EM, Paus R. Epithelial growth control by neuro-trophins: leads and lessons from the hair follicle. Prog Brain Res. 2004;146:493-513.

49. Botchkarev VA, Yaar M, Peters EM, et al. Neurotrophins in skin biology and pathology. J Invest Dermatol. 2006;126(8):1719-1727.

50. Botchkarev VA, Metz M, Botchkareva NV, et al. Brain-derived neurotrophic factor, neurotrophin-3, and neurotrophin-4 act as "epitheliotrophins" in murine skin. Lab Invest. 1999;79(5): $557-572$. 
51. Zhai S, Yaar M, Doyle SM, Gilchrest BA. Nerve growth factor rescues pigment cells from ultraviolet-induced apoptosis by upregulating BCL-2 levels. Exp Cell Res. 1996;224(2):335-343.

52. Stefanato CM, Yaar M, Bhawan J, et al. Modulations of nerve growth factor and Bcl-2 in ultraviolet-irradiated human epidermis. J Cutan Pathol. 2003;30(6):351-357.

53. Vega JA, Garcia-Suarez O, Hannestad J, Perez- Perez M, Germana A. Neurotrophins and the immune system. J Anat. 2003;203(1):1-19.

54. Alleva E, Petruzzi S, Cirulli F, Aloe L. NGF regulatory role in stress and coping of rodents and humans. Pharmacol Biochem Behav. 1996;54(1): 65-72.

55. Arck PC, Handjiski B, Hagen E, Joachim R, Klapp BF, Paus R. Indications for a "brain-hair follicle axis (BHA)": inhibition of keratinocyte proliferation and up-regulation of keratinocyte apoptosis in telogen hair follicles by stress and substance P. FASEB J. 2001;15(13): 2536-2538.

56. Arck PC, Handjiski B, Peters EM, et al. Stress inhibits hair growth in mice by induction of premature catagen development and deleterious perifollicular inflammatory events via neuropeptide substance P-dependent pathways. Am J Pathol. 2003;162(3):803-814.

57. Groneberg DA, Serowka F, Peckenschneider N, et al. Gene expression and regulation of nerve growth factor in atopic dermatitis mast cells and the human mast cell line-1. J Neuroimmunol. 2005;161(1-2):87-92.

58. Raap U, Kapp A. Neuroimmunological findings in allergic skin diseases Curr Opin Allergy Clin Immunol. 2005;5(5):419-424.

59. Raychaudhuri SK, Raychaudhuri SP, Weltman H, Farber EM. Effect of nerve growth factor on endothelial cell biology: proliferation and adherence molecule expression on human dermal microvascular endothelial cells. Arch Dermatol Res. 2005;296(6):291-295.

60. Raap U, Kapp A. Neurotrophins in healthy and diseased skin. G Ital Dermatol Venereol. 2010;145(2):205-211.

61. Ma L, Gao XH, Zhao LP, et al. Brain-derived neurotrophic factor gene polymorphisms and serum levels in Chinese atopic dermatitis patients. J Eur Acad Dermatol Venereol. 2009;23(11):1277-1281.

62. Raap U, Werfel T, Goltz C, et al. Circulating levels of brain derived neurotrophic factor correlate with disease severity in the intrinsic type of atopic dermatitis. Allergy. 2006;61(12):1416-1418.

63. Hoffjan S, Parwez Q, Petrasch-Parwez E, Stemmler S. Variation in the BDNF and NGFB genes in German atopic dermatitis patients. Mol Cell Probes. 2009;23(1):35-38.
64. Panchaprateep R, Korkij W, Asawanonda P. Brain-derived nerve factor and neurotrophins in androgenetic alopecia. Br J Dermatol. 2011; 165(5):997-1002.

65. Sun X, Xu A, Wei X, et al. Genetic epidemiology of vitiligo: a study of 815 probands and their families from south China. Int J Dermatol. 2006; 45(10):1176-1181.

66. Ongenae K, Van Geel N, Naeyaert JM. Evidence for an autoimmune pathogenesis of vitiligo. Pigment Cell Res. 2003;16(2):90-100.

67. Orecchia GE. Neural pathogenesis. In: Hann S, Nordlund J, editors. Vitiligo. Oxford: Blackwell Science Ltd; 2000:142-150.

68. Al'Abadie MS, Senior HJ, Bleehen SS, Gawkrodger DJ. Neuropeptide and neuronal marker studies in vitiligo. Br J Dermatol. 1994; 131(2):160-165

69. Hann SK, Chun W. Autocytotoxic hypothesis for the destruction of melanocytes as the cause of vitiligo. In: Hann SK, Nordlund J, editors. Vitiligo. Oxford: Blackwell Science Ltd; 2000:137-141.

70. Schallreuter KU, Wood JM, Pittelkow MR, et al. Regulation of melanin biosynthesis in the human epidermis by tetrahydrobiopterin. Science. 1994;263(5152):1444-1446.

71. Le Poole IC, van den Wijngaard RM, Westerhof W, Das PK. Tenascin is overexpressed in vitiligolesional skin and inhibits melanocyte adhesion. Br J Dermatol. 1997;137(2):171-178.

72. Lee AY, Kim NH, Choi WI, Youm YH. Less keratinocyte-derived factors related to more keratinocyte apoptosis in depigmented than normally pigmented suction blistered epidermis may cause passive melanocyte death in vitiligo. J Invest Dermatol. 2005;124(5):976-983.

73. Yoshida T, Ishikawa M, Iyo M, Hashimoto K. Serum levels of mature brain-derived neurotrophic factor (BDNF) and its precursor proBDNF in healthy subjects. The Open Clinical Chemical Journal. 2012;5:7-12.

74. Hashimoto K. Sigma-1 receptor chaperone and brain-derived neurotrophic factor: Emerging links between cardiovascular disease and depression. Prog Neurobiol. 2013;100:15-29.

75. Tursich M, Neufeld RW, Frewen PA, et al. Association of trauma exposure with proinflammatory activity: a transdiagnostic meta-analysis. Transl Psychiatry. 2014;4:e413.
Neuropsychiatric Disease and Treatment

\section{Publish your work in this journal}

Neuropsychiatric Disease and Treatment is an international, peerreviewed journal of clinical therapeutics and pharmacology focusing on concise rapid reporting of clinical or pre-clinical studies on a range of neuropsychiatric and neurological disorders. This journal is indexed on PubMed Central, the 'PsycINFO' database and CAS,

\section{Dovepress}

and is the official journal of The International Neuropsychiatric Association (INA). The manuscript management system is completely online and includes a very quick and fair peer-review system, which is all easy to use. Visit http://www.dovepress.com/testimonials.php to read real quotes from published authors. 